\title{
DETERMINANT FACTORS OF COVID-19 TRANSMISSION AMONG OF HEALTH PERSONNEL: A SYSTEMATIC REVIEW
}

\author{
Wenny Wiharsini' ${ }^{1}$, Wahyu Sulistiadi²) \\ 1) Master Program in Public Health, Faculty of Public Health, Universitas Indonesia \\ 2) Faculty of Public Health, Universitas Indonesia
}

\begin{abstract}
Background: The number of Covid-19 infected cases is still increasing, pandemic has yet to be controlled. This can increase the risk of Covid-19 transmission among health personnel in hospitals. Data as of September 7, 2020, the Indonesian Doctors Association (IDI) states that more than 100 doctors in Indonesia who have died due to Covid-19 infection. The phenomenon of transmission in health personnel is urgent. This study aimed to systematically review the determinant factors of covid19 transmission among of health personnel.

Subjects and Method: This was a systematic review study from various article sources that have been done previously. The databases used in this study were Science Direct and Scopus, journals published from February to September 2020. The articles were extracted using the Preferred Reporting System for Systematic Review and Meta-analysis (PRISMA) 2009 flowchart.

Results: Total of 5 articles were reviewed. The results of this study showed that the variables of gender, age, and profession showed significant results on Covid-19 transmission in 2 articles, but the results were not significant in 3 other articles. Meanwhile, the work location variable shows significant results in 2 articles that raise this variable with the location of the work place, including the medical ward and the emergency department. Ethnic variables, raised by one article with insignificant results and for the variable personal protective equipment and masks showed significant results related to Covid-19 transmission.

Conclusion: Workplace arrangements, especially for Covid-19 special isolation and the use of good personal protective equipment, can reduce the transmission of Covid-19 to health personnel, especially those in emergency rooms and medical wards.
\end{abstract}

Keywords: determinants, Covid-19, health personnel, personal protective equipment,

\section{Correspondence:}

Wenny Wiharsini. Universitas Indonesia. Depok, West Java, Indonesia. Email: wennywiharsini@gmail.com. Mobile: 081316790160

\section{BACKGROUND}

Coronavirus Disease 2019 (COVID-19) is an infectious disease caused by Severe Acute Respiratory Syndrome Coronavirus 2 (SARSCoV-2). SARS-CoV-2 is a new type of coronavirus that has never been previously identified in humans. Common signs and symptoms of COVID-19 infection include acute respirtory symptoms such as fever, cough and shortness of breath. The average incubation period is 5-6 days with the longest incubation period of 14 days. Severe cases of COVID-19 can cause pneumonia, acute respiratory syndro- me, kidney failure and even death (Ministry of Health, 2020).

On March 11, 2020, WHO announced that COVID-19 was a global pandemic. This virus is transmitted from human to human and until now the transmission has not been controlled, even in several countries including Indonesia the number of infected cases is still increasing. Data from the Task Force for the Acceleration of Handling Covid-19 as of September 12, 2020, the number of confirmed positive cases in Indonesia was 214,746 people.

The $7^{\text {th }}$ International Conference on Public Health Solo, Indonesia, November 18-19, 2020 |140 https://doi.org/10.26911/the7thicph-FP.01.18 
The fast and high transmission that occurs between humans increases the risk of health workers in hospitals being infected very high, because they interact every day with Covid-19 patients and other patients who are likely to be infected with the virus. Data as of 7 September 2020, the Indonesian Doctors Association (IDI) states that the number of doctors in Indonesia who have died due to Covid-19 infection is more than 100 people, while the data as of September 11 collected by Amnesty Indonesia contained 181 health workers who died, consisting of 112 doctors. and 69 nurses. The phenomenon of transmission in health workers is urgent for research by examining the characteristics of health workers infected with Covid-19. The purpose of this study was to identify the characteristics of health workers that could increase the risk of Covid-19 infection in health workers.

\section{SUBJECTS AND METHOD}

\section{Study Design}

Systematic review was done by searching the database from Scopus and, Science Direct to get relevant publications in accordance with the research objectives. The keywords used in this review include risk factors, Covid-19, and health workers.

\section{Criteria for Inclusion and Exclusion}

The inclusion criteria in this study were scientific journals with the topic of Covid-19 risk factors, the publication period is between February and September 2020, published in English language, while the exclusion criteria for this study were articles published using non-English language, incomplete text, and a systematic review of journals.

\section{Article Extraction}

First, the Author conducts title screening and studies the research abstract that will be used as a reference. If the reference search obtained is considered irrelevant or incomplete or does not match the material, the reference is not included in the group. After the feasibility review process, a journal that meets the requirements in this study is obtained.
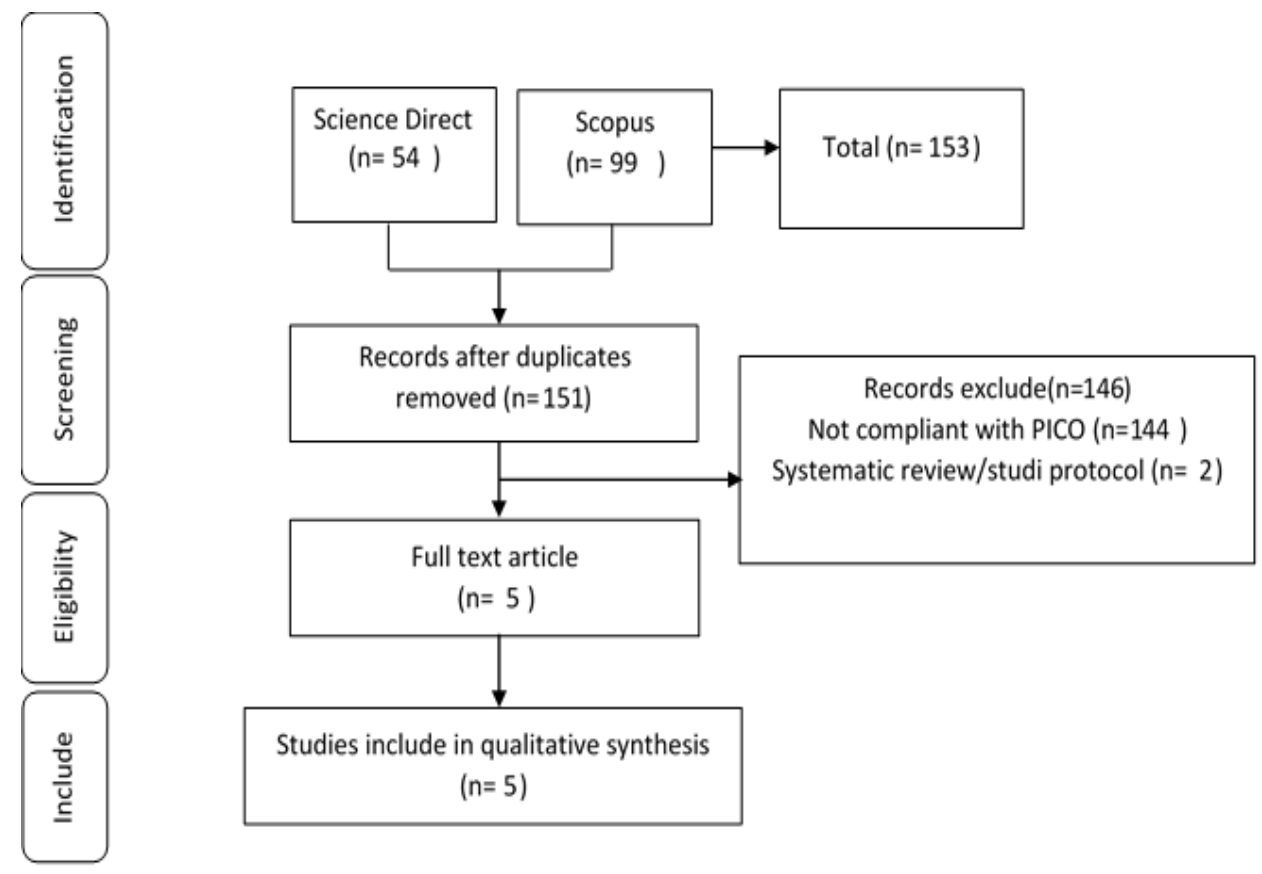

The $7^{\text {th }}$ International Conference on Public Health Solo, Indonesia, November 18-19, $2020 \mid 142$ https://doi.org/10.26911/the7thicph-FP.01.18 
Figure 1. PRISMA Flow Diagram

RESULTS

Table 1. The relationship between the Characteristics of Covid-19 transmission among Health Workers

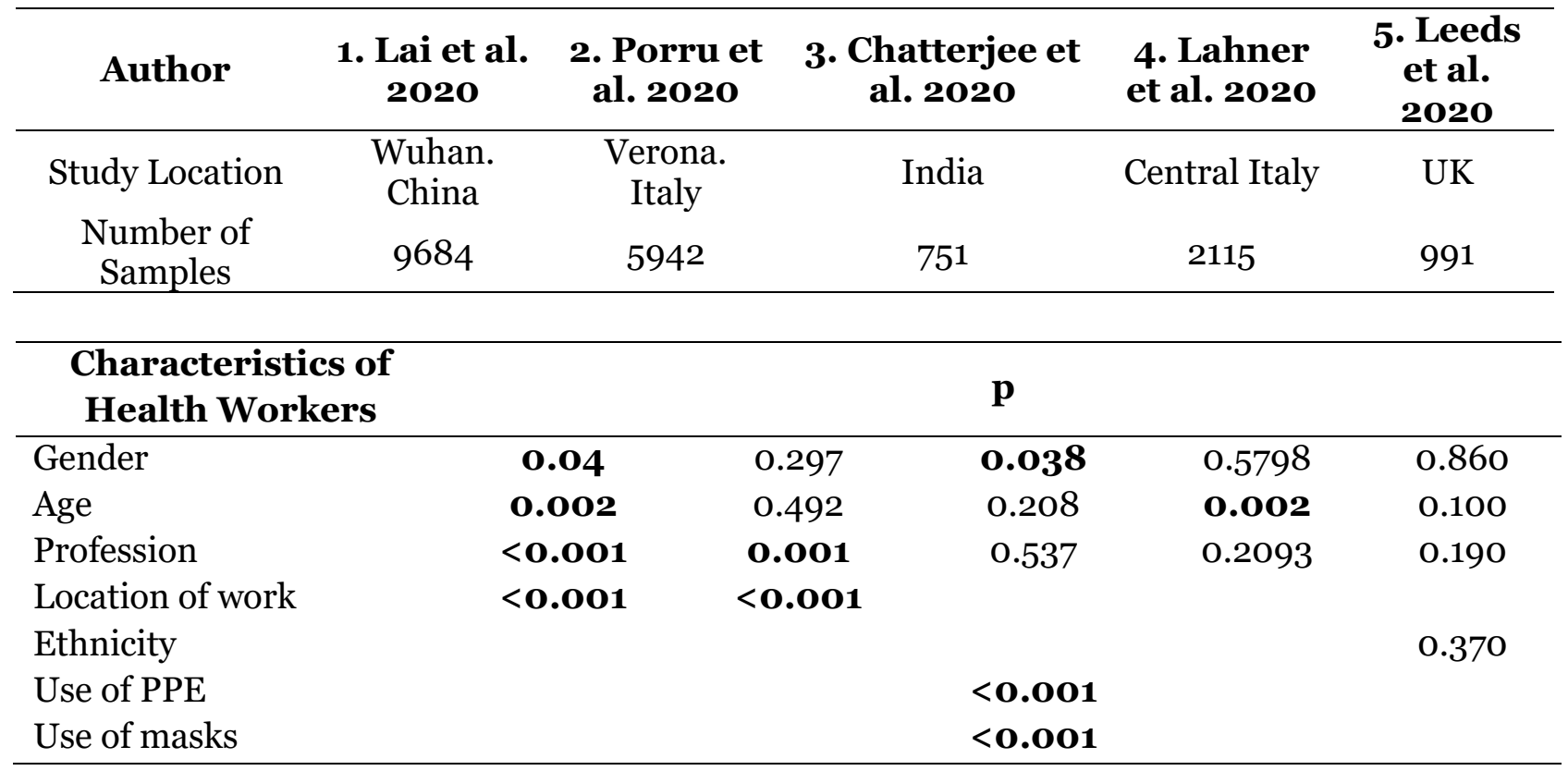

From Table 1. above, it can be seen that only two out of 5 journals show significant sex results on Covid-19 transmission in health workers, but three of the five journals above show that the percentage of women is more infected than men, including journals: number 1, 4, 5. This could be because the workforce in the hospital, especially nurses, is mostly female.

The age variable is only two of the five journals that show results, age is significant for Covid-19 transmission, there are 4 journals that show the age range 22 to $<45$ years old most infected with Covid19, including journal numbers: $1,2,3,4$. Health workers in hospitals start working at the age range of 22 years after completing diploma education, while health workers who are approaching retirement age are unlikely to be placed in a room with a high risk of contracting Covid19.

In the professional variable, two of the five journals that show significant results on the transmission of Covid-19, in each journal have different categories related to profession, but from the five journals above the percentage of nurses is the profession that contracts the most Covid-19 than doctors, this can be due to the intensity of the nurse's interaction with patients more than doctors or other professions.

The location of the workplace is one of the significant variables associated with Covid-19 transmission, from the two journals that raise this variable, the highest percentage of transmission is in the Emergency Unit and the general ward, this can be due to the Emergency Unit being the gateway for all emergency room patients with or without Covid-19. Ethnic variable is a variable that is not widely raised by Authors, and also the results obtained show an insignificant relationship.

The use of personal protective equipment and the use of masks studied in India showed significant results, this shows that The $7^{\text {th }}$ International Conference on Public Health Solo, Indonesia, November 18-19, 2020 |143 https://doi.org/10.26911/the7thicph-FP.01.18 
the transmission of Covid-19 among health conditions can be reduced by providing good personal protective equipment and the discipline of health workers in using Personal Protective Equipment from inserting to removing it. So that training on the use of Personal Protective Equipment in accordance with Standard Operating Procedures is very necessary for every health worker, especially those on the front lines.

Workplace arrangements, especially for Covid-19 screening and isolation and the use of good personal protective equipment, can reduce the transmission of Covid-19 to health workers, especially those in emergency departments and medical wards.

The need to regulate the Covid-19 and Non-Covid-19 zones as well as the determination of the types of personal protective equipment in each zone, so that it is hoped that it can increase awareness for every health worker in the hospital.

\begin{tabular}{c}
\hline REFERENCE \\
\hline Chatterjee, P, Anand, T, Singh, K, Rasaily, R, \\
Singh, R, Das, S, Singh, H, Praharaj, I, \\
Gangakhedkar, R, Bhargava, B \& Pan- \\
da, S (2020). Healthcare workers \& \\
SARS-CoV-2 infection in India: A case- \\
control investigation in the time of \\
COVID-19', Indian Journal of Medical \\
Research, 151 (5): 459-467 \\
Lahner, E, Dilaghi, E, Prestigiacomo, C, Ales- \\
sio, G, Marcellini, L, Simmaco, M, San- \\
tino, I, Orsi, GB, Anibaldi, P, Marcolo-
\end{tabular}

ngo, A, Annibale, B \& Napoli, C (2020). Prevalence of Sars-Cov-2 infection in health workers (HWs) and diagnostic test performance: the experience of a teaching hospital in central Italy, International Journal of Environmental Research and Public Health, 17(12): 112 ,

Lai, X, Wang, M, Qin, C, Tan, L, Ran, L, Chen, D, Zhang, H, Shang, K, Xia, C, Wang, S, Xu, S Wang, W (2020). Coronavirus Disease 2019 (COVID-2019) Infection Among Health Care Workers and Implications for Prevention Measures in a Tertiary Hospital in Wuhan, China', JAMA network open, 3(5): e209666

Leeds, JS, Raviprakash, V, Jacques, T, Scanlon, N, Cundall, J \& Leeds, CM (2020). Risk factors for detection of SARS-CoV2 in healthcare workers during April 2020 in a UK hospital testing programme', EClinicalMedicine

Ministry of Health (2020). Pedoman Pencegahan dan Pengendalian Corona Virus Disease (Covid-19),5: 1-214.

Porru, S, Carta, A, Monaco, MGL, Verlato, G, Battaggia, A, Parpaiola, M, Cascio, GL, Pegoraro, M, Militello, V, Moretti, F \& Tardivo, S (2020). Health surveillance and response to sars-cov-2 mass testing in health workers of a large italian hospital in Verona, Veneto', International Journal of Environmental Research and Public Health, 17(14): 1-11 